\title{
Are they ready? Awareness and preparedness of the emerging workforce for Dental Check by One
}

\author{
Emma Morgan*1 and Laura Gartshore ${ }^{1}$
}

\section{Key points}

Three-year evaluation of the awareness and preparedness of the graduating workforce to deliver dental examinations and preventive care to preschool children.
Identifies the role of dental educators and curricula reform in improving awareness and preparedness for contemporaneous practice.
Identifies the potential role of social media as a non-traditional adjunct to dental education.

\begin{abstract}
Background Dental Check by One (DCby1) is a British Society of Paediatric Dentistry campaign, which aims to increase dental attendance of young children. As the future workforce, dental students have a key role in ensuring its long-term success.

Aims To establish final-year dental students' awareness of DCby1. To evaluate their preparedness for providing dental care for young children and to identify perceived barriers to doing so at the time of graduation as they prepare to enter the workforce.

Materials and methods An anonymous, online survey was administered to graduating final-year dental students in 2018, 2019 and 2020. Quantitative data were gathered using mixed item formats and Likert scales. Qualitative data were also gathered using free-text questions, allowing evaluation of the opinions of responders.

Results The response rate was 83\% ( $n=63)$ in 2018, 91\% ( $n=62)$ in 2019 and 73\% ( $n=57)$ in 2020. Eight percent $(n=5)$ of responders were aware of DCby1 in 2018, improving to $67 \%(n=38)$ in 2020 . Each year, $98 \%$ to $100 \%$ of responders felt prepared to provide preventive care for young children. Fewer than $60 \%$ felt prepared to provide breastfeeding and weaning advice to parents. Responders felt unprepared to examine the dentition of a preschool child. Undergraduate curricula and social media were identified as preferable sources of public health campaign information for students.
\end{abstract}

Conclusion Awareness and preparedness for DCby1 appears to be improving. Ninety-five percent of all responders across three years of study felt prepared to examine a child aged under one year and this is encouraging for the longterm success of DCby1. Targeted curriculum reform including both didactic teaching and online learning platforms appears to have been pivotal to improving undergraduate awareness and preparedness. Social media may offer opportunities for engaging with undergraduate learners.

\section{Introduction}

Early childhood caries (ECC) is defined as 'the presence of one or more decayed (noncavitated or cavitated lesions), missing or filled (due to caries) surfaces, in any primary tooth of a child under six years of age.' ${ }^{1}$ Despite ECC being an almost entirely preventable disease, it affects over 600 million children worldwide, with prevalence data suggesting it affects approximately $17 \%$ of one-year-olds and 36\% of two-year-olds. ${ }^{2}$ In England, 12\%

'School of Dentistry, University of Liverpool, Pembroke Place, Liverpool, L3 5PS, UK.

*Correspondence to: Emma Morgan

Email: Emma.Morgan@liverpool.ac.uk

Refereed Paper.

Accepted 23 January 2021

https://doi.org/10.1038/s41415-021-3574-y of three-year-olds and $25 \%$ of five-year-olds have obvious signs of dental caries. ${ }^{3,4}$ There is widespread acceptance that untreated childhood dental disease is associated with pain, infection, difficulty eating and difficulty sleeping. ${ }^{5}$ Subsequently, a significant number of young children require general anaesthetic for dental extractions, increasing demand and financial pressure on NHS service provision and resources. ${ }^{6,7}$ It is something of a national disgrace that a child in England is having a tooth extracted every ten minutes. ${ }^{6}$

In England, more than $75 \%$ of children aged 0-2 years did not attend the dentist between 2017 and $2020 .^{8,9,10}$ In a bid to encourage early dental attendance, the British Society of Paediatric Dentistry (BSPD) launched 'Dental Check by One' (DCby1) in September 2017. DCbyl is a public health campaign which aims to increase the dental attendance of children aged 0-2 years (https:// dentalcheckbyone.co.uk). ${ }^{11}$ Families are encouraged to take their child for their first dental check-up by the time of their child's first birthday, to allow for early delivery of key preventive messages and to commence acclimatisation to the clinical environment. The campaign endeavours to reduce the caries risk of the UK's youngest members of society and, therefore, reduce the number of children who are experiencing preventable tooth extractions. Population-based oral health campaigns can be both cost-effective and clinically effective in reducing dental caries, improving patient outcomes and reducing financial burden for healthcare providers. ${ }^{7,12}$ It is, therefore, essential that the graduating workforce are aware of such campaigns, so they are prepared to deliver them for the benefit of all stakeholders. 
Each September in the UK, approximately 900 new graduates enter the workforce as dental foundation trainees. New graduates have a key role in implementing the DCbyl campaign in the short term and in ensuring its long-term success. Undergraduates may have limited experience of examining preschool children and this can lead to nervous anticipation of doing so, perhaps precluding new graduates' ability to administer the key messages of DCby1. Outreach placements offer an opportunity to improve undergraduate confidence and can be used to supplement hospital-based training. ${ }^{13,14}$ Children aged under one year tend to present to hospital dental services only following assessment and referral from primary care if extensive dental disease or anomaly is present. Outreach placements based in primary care may, therefore, have an imperative role in providing undergraduates with clinical experience of managing young children. It is important that the graduating workforce feel confident in their ability to provide care to preschool children. The General Dental Council's (GDC's) Preparing for practice determines that registrants should be able to recognise and take account of the needs of different patient groups including children, while underpinning all patient care with a preventive approach that contributes to the patient's long-term oral and general health. ${ }^{15}$ It is, therefore, essential that the emerging workforce are equipped with the skills they need to deliver this care. Previous studies have investigated undergraduate students' confidence in providing care to paediatric patients; however, there is no existing evidence specific to the provision of care for preschool children. ${ }^{13,16}$

A research question arose in relation to final-year dental students' awareness of DCbyl, their preparedness for examining and delivering preventive care for young children, and their perceived barriers to doing so at the time of graduation as they prepare to enter the workforce. Therefore, the aim of this research was to establish final-year dental students' awareness and preparedness for delivering DCbyl.

\section{Materials and methods}

A self-administered, online questionnaire was considered to be the most appropriate method of communicating with the study population in order to address the objectives of the study. Ethical approval was granted by the University of Liverpool (reference number 4982). Item generation was conducted following literature review. Item reduction was completed to restrict the questionnaire length and minimise responder burden. An anonymous, novel survey tool, consisting of 19 questions, was designed using SurveyMonkey. Quantitative data were gathered using mixed item formats and Likert scales. Qualitative data were also gathered using free-text questions, allowing evaluation of the opinions of responders.

The survey tool was piloted in 2018 by a convenience sample of $25 \%$ ( $n=16)$ of fourthyear dental students. Impromptu written and verbal feedback was encouraged to inform development of the tool. The first round of data collection identified further concepts for exploration. The survey was developed accordingly for 2019 and piloted by students who had previously completed the survey in 2018. No changes were made from the 2019 survey which was subsequently disseminated again in 2020. The target population included $100 \%$ of final-year dental students at the University of Liverpool over three years: 2018 $(\mathrm{n}=76), 2019(\mathrm{n}=68)$ and $2020(\mathrm{n}=78)$. The survey was self-administered and anonymous, and participation was voluntary. All final-year students were eligible to participate, negating the need for population sampling.

As participation was voluntary, it was important to engage the interest of responders at an opportune time. In 2018 and 2019, the survey took place before an end of programme paediatric dentistry revision lecture to maximise engagement. Participant information was provided by the first author, who is not a member of the teaching staff. There was no pre-notification of the survey, hence no initiative to review the predictable content. A link to the survey was displayed during the revision lecture and those attending were invited to opt in. Those not in attendance were identified using an attendance record and were contacted directly by e-mail and invited to complete the survey within 24 hours (12 students in 2018 and five in 2019).

In 2020, face-to-face non-clinical teaching was moved online; therefore, the final-year cohort was contacted directly and invited to complete the survey online within 24 hours. Identical information regarding the aims and nature of the survey were provided in each of the three consecutive years. For all rounds of data collection, administration took place at the end of the fifth year in order that responders had completed the paediatric dentistry programme. Final responder data were exported into Microsoft Excel and
NVivo software for analysis. It was planned that missing item data would be excluded from analysis. Quantitative data were analysed using descriptive statistics. Thematic analysis was undertaken on qualitative data gathered from free-text responses. Data were coded using NVivo software and themes were derived as agreed following discussion by the authors.

\section{Results}

A total of 64 responses were received in 2018, 63 in 2019 and 62 in 2020. The following incomplete responses were noted and subsequently excluded from analysis: one in 2018, one in 2019 and five in 2020. Therefore, the response rate was $83 \%(n=63)$ in 2018 , $91 \%(n=62)$ in 2019 and $73 \%(n=57)$ in 2020.

\section{Undergraduate awareness}

\section{Access to dental care}

Almost all responders were aware that NHS dental treatment for children is free of charge; $100 \%(\mathrm{n}=63)$ in $2018,100 \%(\mathrm{n}=62)$ in 2019 and $98 \%(\mathrm{n}=56)$ in 2020. Responders' awareness that a child should have their first dental check-up by age one improved with each year of the study; $94 \%(n=59)$ in $2018,98 \%$ $(n=61)$ in 2019 and $100 \%(n=57)$ in 2020.

\section{Knowledge of oral health campaigns}

The awareness of responders regarding oral health campaigns improved with each year of the study; $35 \%(n=22)$ in $2018,40 \%(n=25)$ in 2019 and $75 \%(n=43)$ in 2020. Awareness of DCbyl similarly improved; $8 \%(n=5)$ of responders identified DCby1 in 2018, 13\% $(\mathrm{n}=8)$ in 2019 and $67 \%(\mathrm{n}=38)$ in 2020 . Responders were aware of other campaigns which aim to promote good oral health such as Childsmile and Smile Month. A majority of responders who identified any oral health campaign stated they learned about such initiatives in dental school (Table 1). Other resources for information regarding oral health campaigns included the BSPD conference ( $5 \% ; n=1$ in 2018 and $2 \% ; n=1$ in 2020), internet browsing (4\%; $n=1$ in 2019) and placements in dental practice $(5 \% ; \mathrm{n}=2$ in 2020). Approximately half of responders each year identified dental school as a preferable source of information and guidance regarding oral health campaigns (Table 1). Alternate suggestions from responders included social media, dental journals and professional bodies. In 2019 and 2020, responders who identified social media resources were asked which 


\begin{tabular}{|c|c|c|c|c|c|c|}
\hline \multirow{2}{*}{\multicolumn{2}{|c|}{ Resource of information and guidance }} & \multicolumn{5}{|c|}{ Source of information } \\
\hline & & $\begin{array}{l}\text { Dental school } \\
\%(n=)\end{array}$ & $\begin{array}{l}\text { Dental } \\
\text { journals } \%(n=)\end{array}$ & $\begin{array}{l}\text { Professional } \\
\text { bodies \% }(\mathrm{n}=)\end{array}$ & $\begin{array}{l}\text { Social media } \\
\%(\mathrm{n}=)\end{array}$ & $\begin{array}{l}\text { Other } \\
\%(n=)\end{array}$ \\
\hline \multirow{3}{*}{ Current resource of information and guidance } & $2018(n=22)$ & $68(n=15)$ & $0(n=0)$ & $9(n=2)$ & $18(n=4)$ & $5(n=1)$ \\
\hline & $2019(n=24)$ & $63(n=15)$ & $4(n=1)$ & $17(n=4)$ & $13(n=3)$ & $4(n=1)$ \\
\hline & $2020(n=43)$ & $74(n=32)$ & $O(n=0)$ & $5(n=2)$ & $14(n=6)$ & $7(n=3)$ \\
\hline \multirow{3}{*}{$\begin{array}{l}\text { Preferable resource of new information and } \\
\text { guidance }\end{array}$} & $2018(n=63)$ & $48(n=30)$ & $3(n=2)$ & $22(n=14)$ & $24(n=15)$ & $3(n=2)$ \\
\hline & $2019(n=62)$ & $44(n=27)$ & $18(n=11)$ & $18(n=11)$ & $21(n=13)$ & $0(n=0)$ \\
\hline & $2020(n=57)$ & $56(n=32)$ & $5(n=3)$ & $16(n=9)$ & $23(n=13)$ & $0(n=0)$ \\
\hline
\end{tabular}

social media platform they would preference. Instagram was consistently the preferable social media platform nominated, with at least two-thirds of responders selecting this each year (Fig. 1).

\section{Undergraduate preparedness \\ Undergraduate experience of examining young children}

In 2019 and 2020, responders were asked whether they had examined a child aged under one year of age during their undergraduate dental studies. Responders were informed that to answer this question positively, the child must not have been personally known to them (for example, own child or a relative examined outside of a dental surgery environment). Those who answered positively were asked where this experience was obtained. Only $6 \%(n=4)$ in 2019 and $7 \%(n=4)$ in 2020 had experience of examining a child aged under one year. These opportunities were provided in a dental hospital setting (25\%; $\mathrm{n}=1$ in 2019 and $75 \% ; \mathrm{n}=3$ in $2020)$ and at outreach placements $(75 \% ; n=3$ in 2019 and $25 \%$; $=1$ in 2020).

\section{Willingness and barriers to examining young children}

Responders were prepared to examine a child aged under one year, with this increasing from $90 \%(\mathrm{n}=57)$ in 2018 to $97 \%(\mathrm{n}=60)$ in 2019 and $96 \%(n=55)$ in 2020. Responders who were not prepared to examine a child aged under one year were asked to identify their barriers to doing so. Responses were thematically analysed, identifying four categories: lack of experience, lack of confidence, perceived patient management issues and concern about causing distress. Perceived patient management issues was the most prevalent theme and was mentioned by responders in every year.

Fig. 1 Preferable social media platforms for information and guidance in dentistry, as identified by undergraduate responders

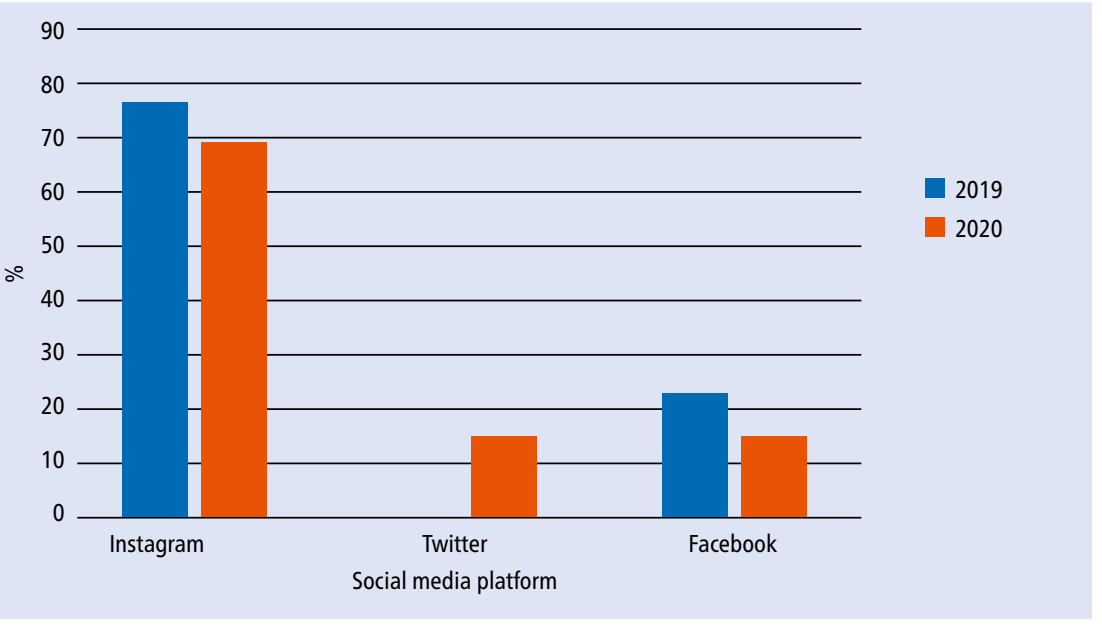

Preparedness to provide preventive care for young children

At least $98 \%$ of responders each year agreed that they felt confident to provide preventive dental care to young children according to evidence-based practice guidelines (Table 2). Furthermore, at least $93 \%$ also felt confident to share preventive advice with other healthcare professionals (Table 2). Responders felt less confident to provide parents with breastfeeding and weaning advice, with fewer than $60 \%$ feeling confident to provide such advice (Table 2). In 2019 and 2020, responders who did not feel confident to provide breastfeeding and weaning advice were asked to identify their barriers to doing so. Responses were thematically analysed into five categories: lack of experience, lack of knowledge, lack of awareness, patient management and gender barriers.

\section{Confidence in examining dentitions}

Children's dentitions were categorised into four groups: preschool, primary, mixed and permanent. Although preschool is not a specified dentition, this was used to represent examination of preschool-aged children in this survey and was explained as such. Responders were asked to rank the four dentitions according to their self-reported confidence of examining them, with a score of 1 being assigned to the most confident preference and a score of 4 to the least confident preference. Responders in all years of the survey felt most confident to examine a child in the permanent dentition, followed by a child in the primary dentition, before a child in the mixed dentition. Responders reported least confidence in examining the dentition of a preschool-aged child.

\section{Discussion}

This study was designed to evaluate awareness of DCbyl in the emerging workforce and their preparedness to deliver the oral health messages at the heart of the campaign. It identified key areas for development for dental education, including 
Table 2 Preparedness of undergraduate responders to provide preventive advice to young children, to share preventive care with other healthcare professionals and to provide breastfeeding and weaning schedules to families

\begin{tabular}{l|l|l|l|l|l}
\multicolumn{2}{|c|}{} & $\begin{array}{l}\text { Strongly agree } \\
\%(n=)\end{array}$ & $\begin{array}{l}\text { Agree } \\
\%(n=)\end{array}$ & $\begin{array}{l}\text { Disagree } \\
\%(n=)\end{array}$ & $\begin{array}{l}\text { Strongly disagree } \\
\%(n=)\end{array}$ \\
\hline \multirow{2}{*}{$\begin{array}{l}\text { I am confident to provide preventive dental } \\
\text { care to the families of young children }\end{array}$} & $2018(n=63)$ & $54(n=34)$ & $46(n=29)$ & $0(n=0)$ & $0(n=0)$ \\
\cline { 2 - 6 } & $2019(n=62)$ & $61(n=38)$ & $37(n=23)$ & $2(n=1)$ & $0(n=0)$ \\
\cline { 2 - 6 } & $2020(n=57)$ & $54(n=31)$ & $46(n=26)$ & $0(n=0)$ & $0(n=0)$ \\
\hline \multirow{2}{*}{$\begin{array}{l}\text { I would feel confident to provide advice about } \\
\text { evidence-based preventive care to other } \\
\text { healthcare professionals }\end{array}$} & $2018(n=63)$ & $27(n=17)$ & $70(n=44)$ & $3(n=2)$ & $0(n=0)$ \\
\cline { 2 - 6 } & $2019(n=62)$ & $37(n=23)$ & $61(n=38)$ & $2(n=1)$ & $0(n=0)$ \\
\hline \multirow{2}{*}{$\begin{array}{l}\text { I am confident to provide families with advice } \\
\text { on breastfeeding and appropriate weaning } \\
\text { schedules }\end{array}$} & $2020(n=57)$ & $47(n=27)$ & $46(n=26)$ & $7(n=4)$ & $0(n=0)$ \\
\cline { 2 - 6 } & $2018(n=63)$ & $6(n=4)$ & $30(n=19)$ & $51(n=32)$ & $13(n=8)$ \\
\hline & $2019(n=62)$ & $18(n=11)$ & $42(n=26)$ & $40(n=25)$ & $0(n=0)$ \\
\hline
\end{tabular}

awareness of population-based oral health campaigns, preparedness to examine preschool-aged children, and preparedness to deliver breastfeeding and weaning advice.

To enhance awareness of oral health campaigns among undergraduate students, it is important that methods favourable to the engagement of undergraduate learners are employed. In this study, dental school was consistently identified as the most common, and the most preferable, resource for this information. This demonstrates the key role dental educators have in disseminating contemporaneous public health information to the emerging workforce. Responders consistently reported wanting to receive additional information about populationbased oral health campaigns such as DCby 1 from dental journals and professional bodies. Educators have a role in signposting students to peer-reviewed journals and enabling them to develop critical appraisal skills. These skills are important in order to facilitate future independent evidence-based practice.

Social media was identified as an alternate preferable resource by almost a quarter of all responders. Social media is widely accessible, free and responsive, allowing for rapid dissemination of new information. Such functionalities make it a useful educational resource for the workforce pre- and postqualification. The use of social media as an educational tool has been previously described as an interactive, collaborative learning environment and teaching adjunct. ${ }^{17,18}$ Twitter is a popular platform for dissemination of scientific research; however, this study revealed it to be less popular with the student body when compared to Instagram. ${ }^{19}$ Instagram has increased in popularity over the past five years to reach 766 million users by $2019 .{ }^{20}$ Instagram is popular with millennials; $64 \%$ of users are aged between 18 and $34 .{ }^{21}$ However, in the absence of any peer review process for social media content, there may be concerns regarding the reliability of information available. ${ }^{22,23}$ Furthermore, it is recommended that dental students are made aware of the GDC's guidance on the use of social media. ${ }^{24}$ There is, nevertheless, scope for public health campaigners and dental educators to promote and develop the availability of evidence-based learning material via Instagram to engage the student-aged population. The BSPD has presence on multiple social media platforms (for example, @BSPDUK), providing up-todate news and evidence-based guidance that dental students can be directed to with regards to DCby1.

A small minority of students within this study had experience of examining a child aged under one year in the dental hospital setting and at outreach placements. Despite this, $95 \%$ of all responders in the three years of this study felt prepared to examine a child aged under one year. This is encouraging for the long-term success of DCby1. Despite consistently low levels of hands-on experience, the emerging workforce's self-reported preparedness to provide care for preschoolaged children improved over the course of this study. In 2020, 100\% of responders reported confidence in providing preventive advice for young children - a fundamental aspect of the DCbyl campaign. Previous studies have shown that dental students demonstrate high levels of self-perceived confidence in the delivery of preventive care to both paediatric and adult patients. ${ }^{13,25}$ This suggests that the skills required for the delivery of preventive care may be transferable.

In this study, the majority of students self-reported confidence to share oral health advice for young children with other healthcare professionals. This positive finding creates the opportunity for collaborative working between the dental workforce and healthcare colleagues. The provision of breastfeeding and weaning advice remains the area of greatest apprehension for undergraduate preparedness. There is no previously reported research regarding dentists' confidence to provide breastfeeding and weaning advice before this study; however, a lack of knowledge and confidence to provide breastfeeding and weaning advice among healthcare professional students has been highlighted. ${ }^{26,27}$ Infant feeding education was incorporated into undergraduate teaching at the University of Liverpool in 2019. Consequently, self-reported confidence to provide breastfeeding and weaning advice improved from $36 \%$ of responders in 2018 to $58 \%$ in 2020 .

Implementation of the findings of this study have influenced the development of novel undergraduate curricula at the University of Liverpool. The principles of providing care for preschool-aged children have been incorporated into small and large group didactic teaching. Aligned learning outcomes are supported with a virtual learning platform that hosts a range of evidence-based and interactive resources including podcasts and videos. Videos demonstrating how to position a young child 
safely and comfortably for examination have been created by the authors (Figures 2 and 3; Box 1). The videos were developed to be used as a teaching aid to improve undergraduate confidence as has previously been successful within paediatric dentistry. ${ }^{28,29}$ These videos are available for British Dental Journal readers to download and share at: https:// tinyurl.com/kneetokneeexam and https:// tinyurl.com/preschoolexam.

In the wake of COVID-19, a blended learning approach, incorporating clinical sessions with online learning, has become the new normal in universities across the UK. It is likely that the role of virtual learning platforms will become increasingly important within dental education. ${ }^{30}$ As a result of this study, there was significant development of the virtual learning platform in paediatric dentistry and this has highlighted the range of innovative opportunities which online learning offers.

In 2018, the BSPD nominated the first author of this study as undergraduate ambassador for DCbyl, with the aim of increasing awareness of DCbyl among undergraduate dental students in the UK. To date, the principles of DCbyl, and hints and tips for delivering key preventive messages for preschool children, have been presented to dental foundation trainees across North West England and have been published in BDJ Student. ${ }^{31}$

It is suggested that the steps taken at the University of Liverpool for targeted training in relation to examination and preventive dental care for preschool children is considered at other UK dental schools, if it is not yet in place. Undergraduates at Liverpool attend 'prevention clinics' within the dental hospital throughout their programme. These clinics offer an opportunity to examine and deliver preventive care to children at high risk of disease. All children who attend the hospital following referral with caries must attend these clinics, providing a wealth of learning resource for students and optimising access to preventive care for patients. If this experience is similar across the UK, it is of interest whether the results of this study are generalisable to the wider student body, or whether local variation exists according to student demographics or learning formats. It is possible that a self-reported lack of confidence in examining the dentition of a young child and in delivering potentially sensitive weaning advice is prevalent. If so, the development of evidence-based learning

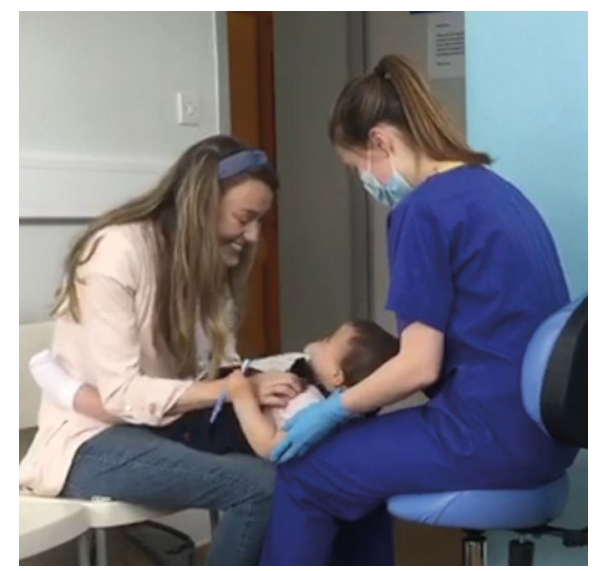

Fig. 2 Example of demonstrating how to position a young child safely and comfortably for examination

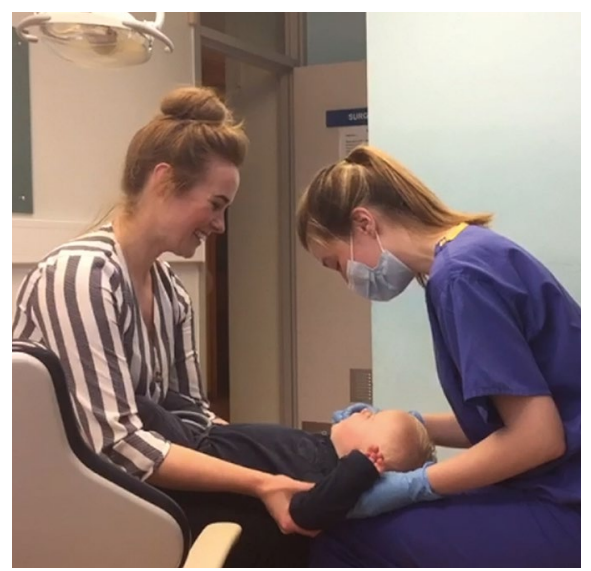

Fig. 3 Example of demonstrating how to position a young child safely and comfortably for examination

\section{Box 1 Top tips for delivering a knee-to-knee examination for a young child}

1. The clinician must sit knee-to-knee with the child's carer. This can be on the side of the lowered dental chair, or on any other suitable chair in the surgery

2. The child should sit on the carer's knee, facing the carer for reassurance, and with their legs around the carer's waist

3. The child is gently lowered back so that the child's head is in the clinician's lap. The carer should hold the child to support them and to offer further reassurance

4. It is helpful if the carer or clinician can sing a favourite nursery rhyme. For older toddlers, it helps to count slowly and gently out loud to ten. Don't forget to smile!

5. A toothbrush may be used to persuade the child to open their mouth

6. A young child may not be able to cope with a full examination; reassure the family that compliance will improve as the child becomes more familiar with the dental environment. It is important to stress the benefits of trying the knee-to-knee exam so that the child can gradually learn that nothing bad happens! Acceptance is often rapid if the exam is repeated at each check-up starting from age one resulting in a happier and more confident dental visit for the toddler and school-aged child

7. Even a brief, limited exam is helpful for acclimatisation, reinforcing the role of check-ups to families and in identifying cavitated carious lesions

8. Ensure that families understand that acclimatisation of this nature allows an older child to accept non-invasive preventive care such as fluoride varnish application and placement of preformed metal crowns if they are required in the future - avoiding the need for preventable extractions.

resources that target the delivery of care for young children may be welcomed by dental students across the UK.

Surveys are commonly used to determine undergraduate experience and confidence and were deemed appropriate to answer the research question raised in this study. ${ }^{13,14,25} \mathrm{~A}$ self-administered, online survey was a practical and effective method of engaging the target population, allowing for rapid data collection. It is noted that there may be a degree of social bias at play if students have exaggerated their preparedness to deliver preventive care shortly before graduation, despite the anonymous nature of the survey, and that the results should be interpreted with caution. Likewise, it is possible that the self-reported preparedness of undergraduates may not reflect their skill or learning needs. ${ }^{32}$ There may be a degree of performance bias impacting the results of 2019 , as 16 students within this cohort piloted the 2018 survey. The survey was, however, developed between 2018 and 2019 as described in the method and this, coupled with the lack of pre-notification of the survey, is considered to reduce the impact of any resulting performance bias. All final-year students were eligible to participate, and it is assumed that the baseline demographics of the University of Liverpool cohort are representative of those at other UK universities. The eligible population included both undergraduate and postgraduate entry 
programmes. Female students accounted for $65 \%$ of the target population and this is representative of the $63 \%$ of UK dental graduates who are female. ${ }^{33}$

Consistently high response rates at a minimum of $73 \%$ were achieved each year, producing more precise data for analysis and improving generalisability to the wider undergraduate population. Response rate was enhanced when the survey was administered at the face-to-face revision lecture in 2018 and 2019, rather than during 2020's online teaching, although this is perhaps not surprising. Despite the limitations of a survey methodology, the study presents some strengths and is the first of its kind. The findings will inform development of DCbyl and could be more widely considered by dental educators and by those who design oral health campaigns.

\section{Conclusion}

Final-year dental students' awareness and preparedness for DCbyl improved over the course of this study, the findings of which progressively informed curricula development year on year. Targeted curricula reform and engagement using a range of techniques such as didactic teaching and virtual learning platforms has been pivotal in improving awareness and preparedness, and in emphasising the role of dental educators. With the reduction of face-to-face teaching due to COVID-19, the role of online learning has become increasingly important within dental curricula, with videos being a useful technique to prepare students for future clinical sessions. Social media usage is prevalent within the student body and should be considered as a non-traditional resource for dental education.

Ethics declaration

No funding was received for the completion of this research project. No conflicts of interest were identified.

\section{References}

1. Pitts N, Baez R, Diaz-Guallory C et al. Early childhood Caries: IAPD Bangkok Declaration. Int J Paediatr Dent 2019; 29: 384-386.
2. Tinanoff N, Baez R J, Diaz-Guillory C. Early childhood caries epidemiology, aetiology, risk assessment, societal burden, management, education, and policy: Global perspective. Int J Paediatr Dent 2019; 29: 238-248.

3. Public Health England. Oral health survey of threeyear-old children 2013: A report of the prevalence and severity of dental decay. 2014. Available at https:// assets.publishing.service.gov.uk/government/uploads/ system/uploads/attachment_data/file/773621/ Oral health_survey_of 3 year_old_children_2013. pdf (accessed October 2020).

4. Public Health England. National Dental Epidemiology Programme for England: oral health survey of 5-yearolds 2019 - A report on the variations in prevalence and severity of dental decay. 2020. Available at https:// assets.publishing.service.gov.uk/government/uploads/ system/uploads/attachment_data/file/873492/ NDEP_for_England_OH_Survey_5yr_2019_v1.0.pdf (accessed October 2020).

5. BaniHani A, Deery C, Toumba J, Munyombwe T, Duggal $M$. The impact of dental caries and its treatment by conventional or biological approaches on the oralhealth related quality of life of children and carers. Int J Paedatr Dent 2018: 28: 226-276.

6. Public Health England. Every 10 minutes a child in England has a rotten tooth removed. 2018. Available at https://www.gov.uk/government/news/every10-minutes-a-child-in-england-has-a-rotten-toothremoved (accessed October 2020).

7. Public Health England. Health Matters: child dental health 2017. Available at https://www.gov.uk/government/ publications/health-matters-child-dental-health/healthmatters-child-dental-health (accessed October 2020).

8. NHS Digital. NHS Dental Statistics for England 2017-18 Annual Report. 2018. Available at https://digital.nhs.uk/ data-and-information/publications/statistical/nhs-dentalstatistics/2017-18-annual-report (accessed October 2020).

9. NHS Digital. NHS Dental Statistics for England 2018-19, Annual Report. 2019. Available at https://digital.nhs. uk/data-and-information/publications/statistical/nhsdental-statistics/2018-19-annual-report-pas (accessed October 2020).

10. NHS Digital. NHS Dental Statistics for England 2019-20, Annual Report. 2020. Available at https://digital.nhs. uk/data-and-information/publications/statistical/ nhs-dental-statistics/2019-20-annual-report (accessed October 2020).

11. British Society of Paediatric Dentistry. Dental Check by One to improve oral health in UK children. 2018. Available at https://www.bspd.co.uk/Portals/0/ National\%20launch\%20for\%20Dental\%20Check\%20 by $\% 200$ ne $\% 20$ campaign $\% 20$ final\%2022-09.pdf (accessed October 2020)

12. Fraihat N, Madae'en S, Bencze Z, Herczeg A, Varga 0 . Clinical Effectiveness and Cost-effectiveness of OralHealth Promotion in Dental Caries Prevention among Children: Systematic Review and Meta-Analysis. Int IEnviron Res Public Health 2019; 16: 2668.

13. Rodd H D, Farman M, Albadri S, Mackie I C Undergraduate experience and self-assessed confidence in paediatric dentistry: comparison of three UK dental schools. Br Dent J 2010; 208: 221-225.

14. Walley S, Bailey J R, Albadri S, Mackie I C, Gilchrist $F$, Rodd H D. Undergraduates' self-reported clinical experience, confidence and perspectives of hospital and outreach paediatric dentistry: a three-year multi-centre evaluation. Br Dent J 2014; 216: 251-256.

15. General Dental Council. Preparing for Practice. 2015 Available at https://www.gdc-uk.org/docs/defaultsource/quality-assurance/preparing-for-practice(revised-2015).pdf (accessed October 2020).
16. Seddon R P. Undergraduate experience of clinical procedures in paediatric dentistry in a UK dental school during 1997-2001. Eur J Dent Educ 2004; 8: 172-176.

17. McAndrew $M$, Johnston A E. The role of social media in dental education. J Dent Educ 2012; 76: 1474-1481.

18. Wanner G K, Philips A W, Papanagnou D. Assessing the use of social media in physician assistant education. Int J Med Educ 2019; 10: 23-28.

19. Klar S, Krupnikov Y, Ryan J B, Searles K, Shmargad Y. Using social media to promote academic research: Identifying the benefits of Twitter for sharing academic work. PLoS One 2020; DOI: 10.1371/journal. pone. 0229446

20. Statista. Number of Instagram users worldwide from 2016 to 2023. 2019. Available at https://www.statista. com/statistics/183585/instagram-number-of-globalusers/ (accessed October 2020).

21. Statista. Distribution of Instagram users worldwide as of April 2020, by age and gender. 2020. Available at https://www.statista.com/statistics/248769/agedistribution-of-worldwide-instagram-users/ (accessed October 2020).

22. Misch C M. Editorial: Instagram-based dentistry. Int J Oral Implantol (Berl) 2019; 12: 391-392.

23. Spallek H, Turner S P, Donate-Bartfield E et al. Social Media in the Dental School Environment, Part B: Curricular Considerations. J Dent Educ 2015; 79: 1153-1166.

24. General Dental Council. Guidance on using Social Media. 2016. Available at https://www.gdc-uk.org/ docs/default-source/guidance-documents/guidanceon-using-social-media.pdf?sfvrsn=de158345_2 (accessed October 2020)

25. Gilmour A S M, Welply A, Cowpe J G, Bullock A D, Jones $R$ J. The undergraduate preparation of dentists: Confidence levels of final year dental students at the School of Dentistry in Cardiff. Br Dent J 2016; 221: 349-354.

26. Shu-Fei Y, Yenna S, Elaine B, Virginia S. Breastfeeding knowledge and attitudes of health professional students: a systematic review. Int Breastfeed J 2018; 13: 8 .

27. Gary A J, Birmingham E E, Jones L B. Improving breastfeeding medicine in undergraduate medical education: A student survey and extensive curriculum review with suggestions for improvement. Educ Health (Abingdon) 2017; 30: 153-168.

28. Kenny K P, Day P F, Alkazme A M. The effect of viewing video clips of paediatric local anaesthesia administration on the confidence of undergraduate dental students. Eur J Dent Educ 2018; DOI: 10.1111/ eje.12257.

29. Kalwitzki M. Self-reported changes in clinical behaviou by undergraduate dental students after video-based teaching in paediatric dentistry. Eur J Dent Educ 2005 9: 108-114.

30. Iyer P, Aziz K, Ojcius D M. Impact of COVID-19 on dental education in the United States. J Dent Educ 2020; 84: 718-722.

31. Morgan E, Gartshore L. What is DCby1? BDJ Student 2019; 26: 12-13.

32. Honey J, Lynch C D, Burke F M, Gilmour A S M. Ready for practice? A study of confidence levels of final year dental students at Cardiff University and University College Cork. Eur J Dent Educ 2011; 15: 98-103.

33. Christie and Co. The Dental Industry 2018: Staffing, Brexit and The Dentist Shortage. 2018. Available at https://www.christie.com/christieMediaLibraries/ christie/PDFs-Publications/Dental/CCO-The-DentalIndustry-2018.pdf?ext=.pdf (accessed October 2020). 